\title{
DIRECT DIELECTRIC BARRIER DISCHARGE IONIZATION PROMOTES RAPID AND SIMPLE LUBRICANT OIL FINGERPRINTING
}

Tatiana de O. Zuppa Neto ${ }^{a}$, Tahereh G. Avval ${ }^{b}$, Pedro A. de Oliveira Morais ${ }^{c}$, Wade C. Ellis ${ }^{\mathrm{d}}$, Sean C. Chapman ${ }^{\mathrm{b}}$, Anselmo E. de Oliveirac ${ }^{\mathrm{c}}$, Matthew R. Linford ${ }^{\mathrm{b}}$, Paul B. Farnsworth ${ }^{\mathrm{b}}$, Nelson R. Antoniosi Filhoa*.

aExtraction and Separation Methods Laboratory, Chemistry Institute, Federal University of Goias, CP.131, Goiânia, GO 74001-970, Brazil. + 5562 35211221

bDepartment of Chemistry and Biochemistry, Brigham Young University, Provo, UT 84602, USA.

cTheoretical and Computational Chemistry Laboratory, Chemistry Institute, Federal Universiry of Goias, Goiânia, GO 74690-900, Brazil.

dBakersfield College, 1801 Panorama Dr, Bakersfield, CA 93306, USA.

*Corresponding Author: nlliantoniosi@hotmail.com 


\section{TABLES}

Table S1. Operating parameters of the mass spectrometer.

\begin{tabular}{l|c}
\hline \multicolumn{1}{c|}{ Parameter } & Value \\
\hline End plate Offset & $500 \mathrm{~V}$ \\
\hline Capillary & $-500 \mathrm{~V}$ \\
\hline Dry gas & $4.0 \mathrm{~L} / \mathrm{min}$ \\
\hline Dry gas temperature & $250^{\circ} \mathrm{C}$ \\
\hline Acquisition rate & $1.00 \mathrm{~Hz}$ \\
\hline Rolling average & 2 \\
\hline Capillary exit & $140.0 \mathrm{~V}$ \\
\hline Skimmer 1 & $46.7 \mathrm{~V}$ \\
\hline Hexapolo 1 & $23.0 \mathrm{~V}$ \\
\hline Hexapolo rf & $125.0 \mathrm{~V} \mathrm{p}-\mathrm{p}$ \\
\hline Skimmer 2 & $23.3 \mathrm{~V}$ \\
\hline Lens 1 Transfer & $37.6 \mu \mathrm{s}$ \\
\hline Lens 1 Pre Pulse Storage & $1.0 \mu \mathrm{s}$ \\
\hline
\end{tabular}


Table S2. Principal Loadings of PCA of ALOs samples.

\begin{tabular}{c|c|c}
\hline PC1 & PC2 & PC3 \\
\hline \multicolumn{3}{|c}{ Principal Negative loadings } \\
\hline 130.94 & 130.94 & 130.94 \\
\hline 172.98 & & 172.98 \\
\hline \multicolumn{3}{|c}{ Principal Positive loadings } \\
\hline 168.06 & 220.20 & 170.09 \\
\hline 169.09 & 296.27 & 296.22 \\
\hline 170.09 & 297.26 & \\
\hline 171.10 & & \\
\hline 184.07 & & \\
\hline 186.089 & &
\end{tabular}

\section{FIGURES}
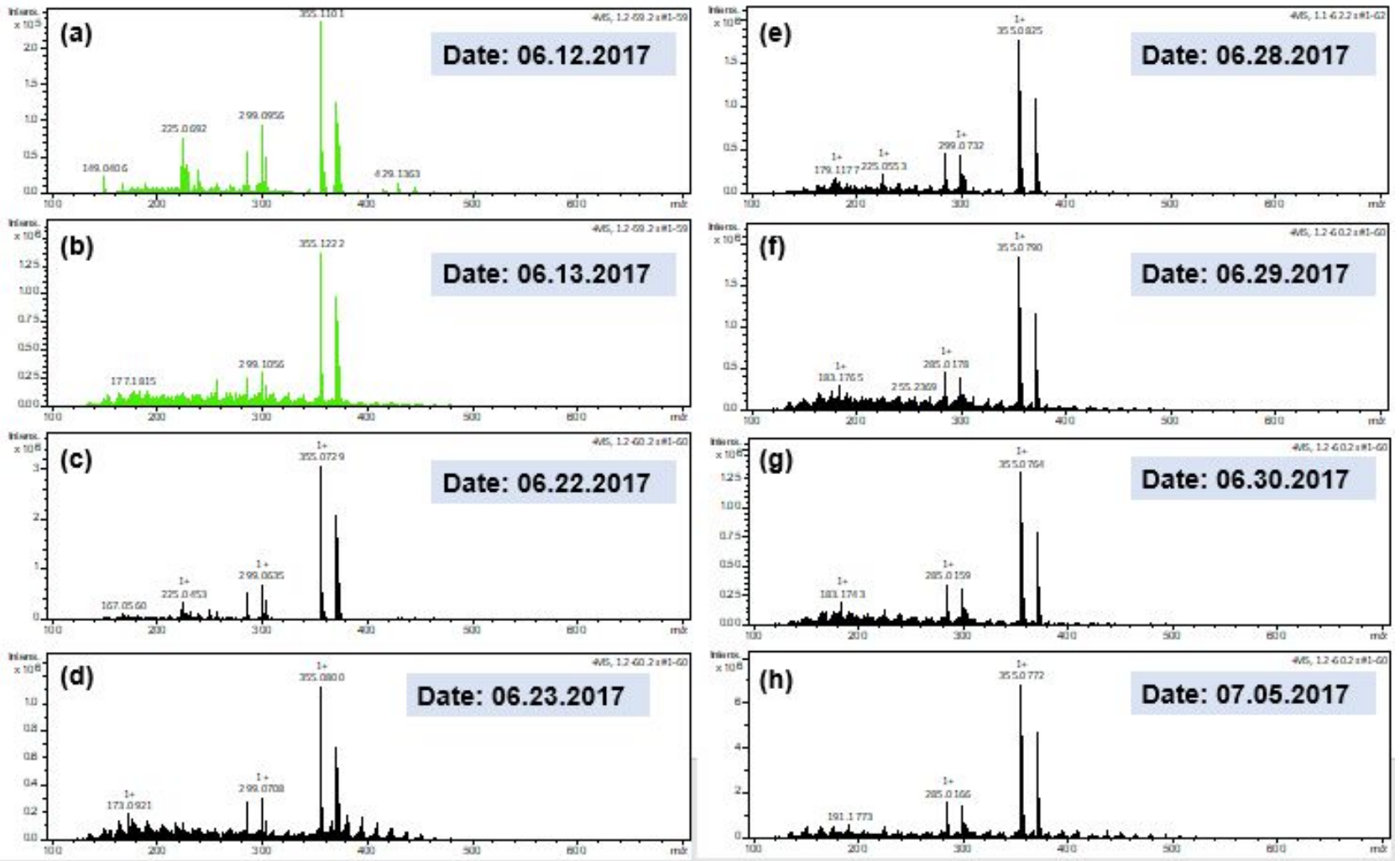

Figure S1. Blanks DBDI-TOFMS mass spectra at different days of analysis.

Samples that were analyzed at (a) A1, A5, A7, A8, and D1; (b) A1 and A3; (c) A2, 
A4, A6, D2, D6, and E1; (d) D3, D4, D5, and D7; (e) C1, C3, C5, C8, and C9; (f)

C2, C4, C6, C7, B5, and B10; (g) B2 and B3; and (h) B1, B4, B6, B7, B8, and B9.
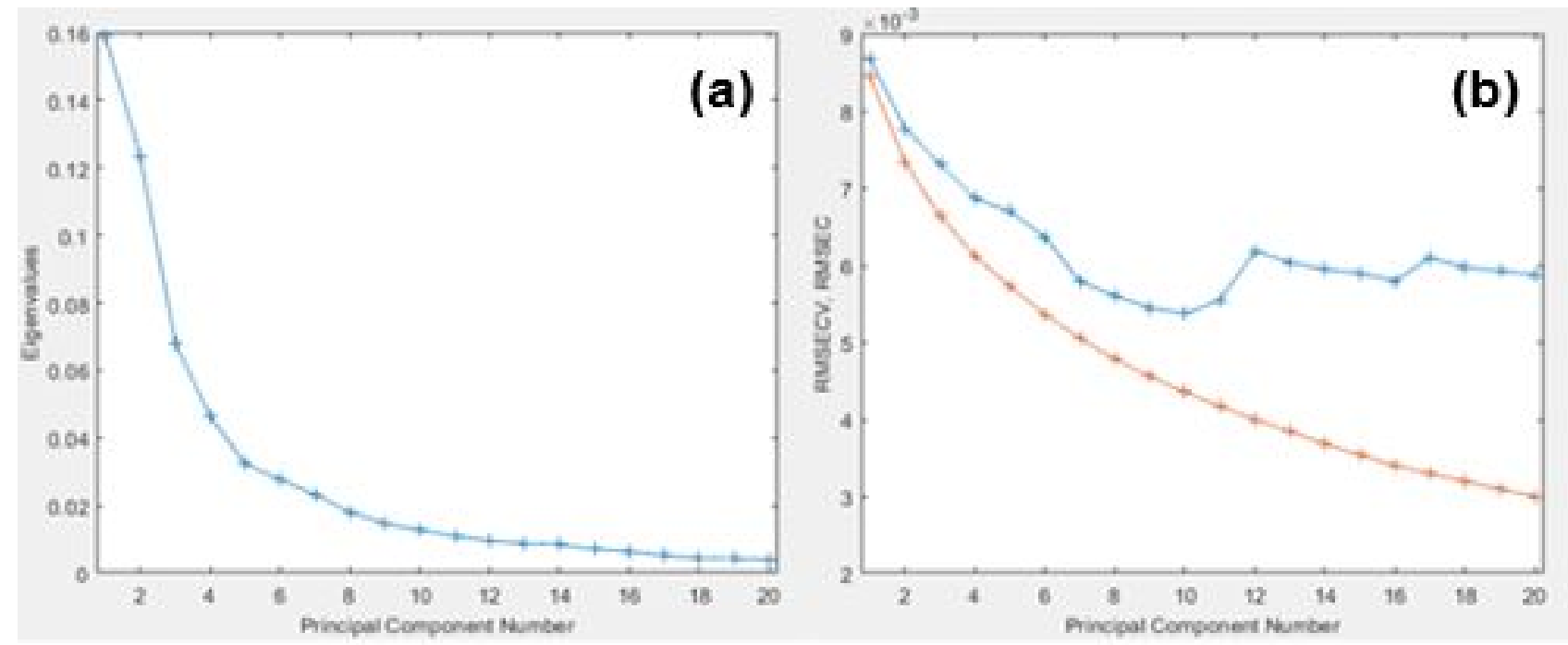

Figure S2. Scree plot for the PCA of the DBDI-TOFMS spectra from the profile of the 35 ALOs samples. (a) Eingenvalues and (b) RMSECV and RMSEC as a function of the PCA model dimensionality.

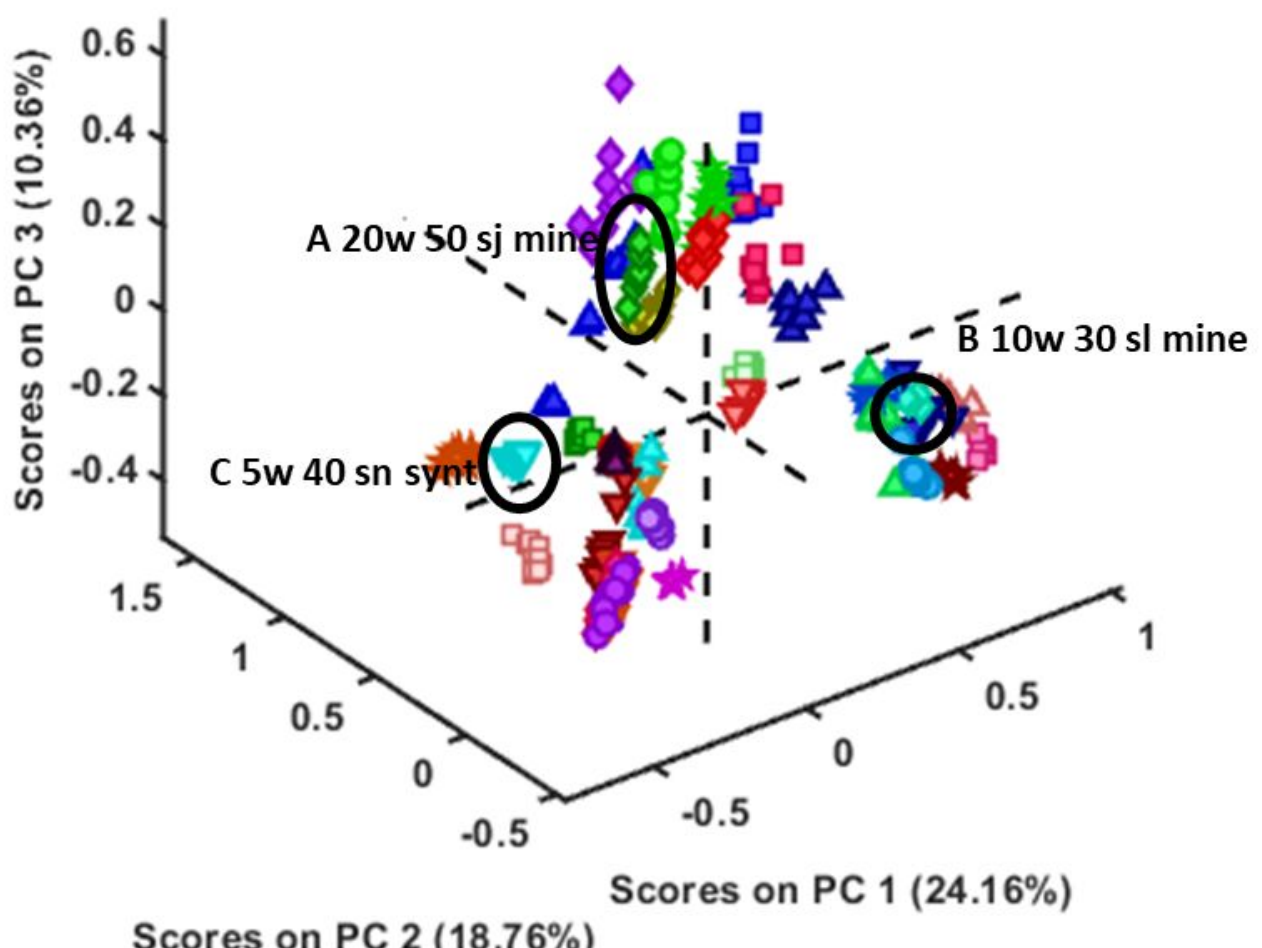


Figure S3. The ability of PCA to separate the three mass spectra shown in figure three from brands $A, B$ and $C$.
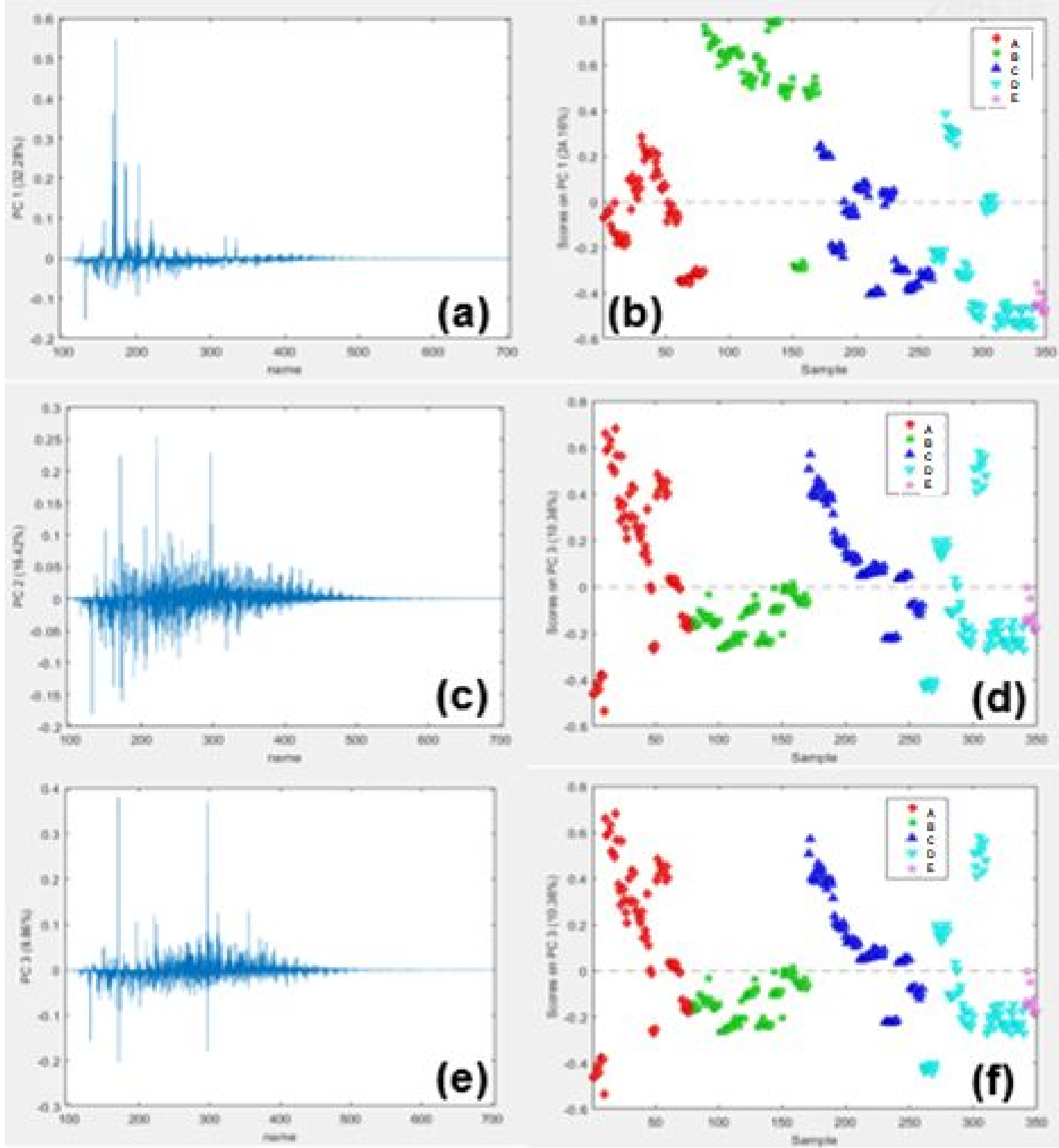

Figure S4. PCs 1-3 from PCA model of DBDI-TOFMS spectra from the profile of the ALOs samples. Loadings on (a) PC1, (c) PC2, and (e) PC3 as a function of 
the mass (u) and scores plots on (a) PC1, (c) PC2, and (e) PC3 as a function of the mass spectra.

(a)

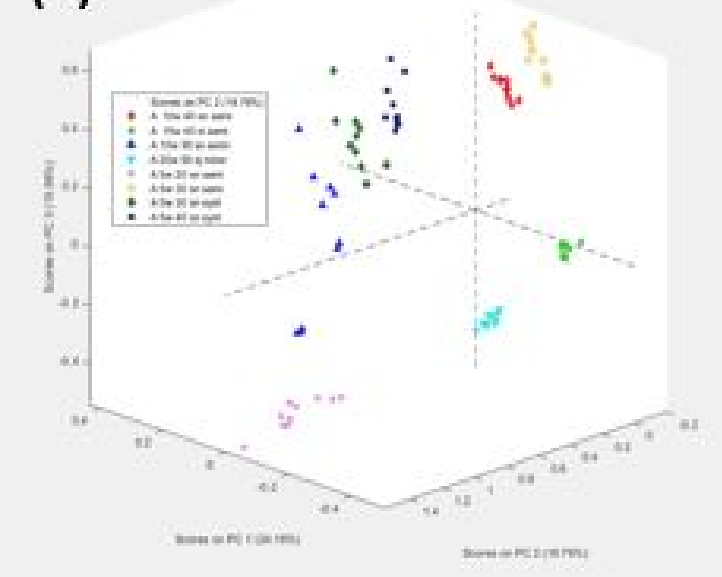

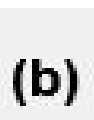

(b)

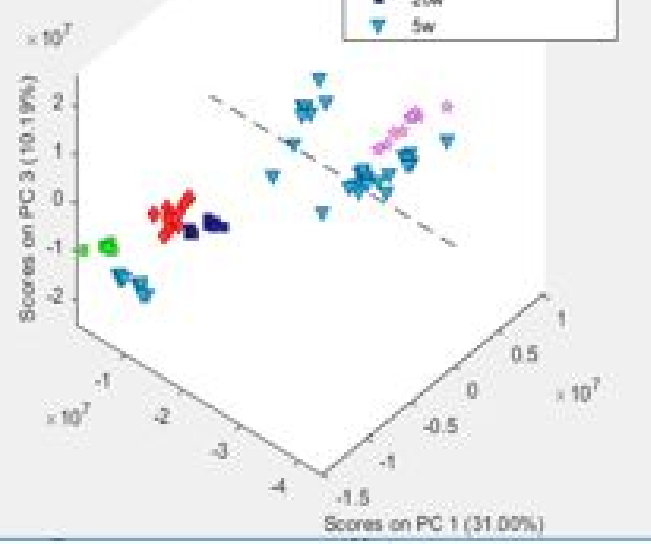

Figure S5. Three-dimensional scores plot from the PCA analysis determined from mass spectra for the brand A samples showing base oil type distinction (a) and low SAE classification distinction (b). The data was preprocessed with mean centering, 1-Norm and Poisson scaling.

(a)

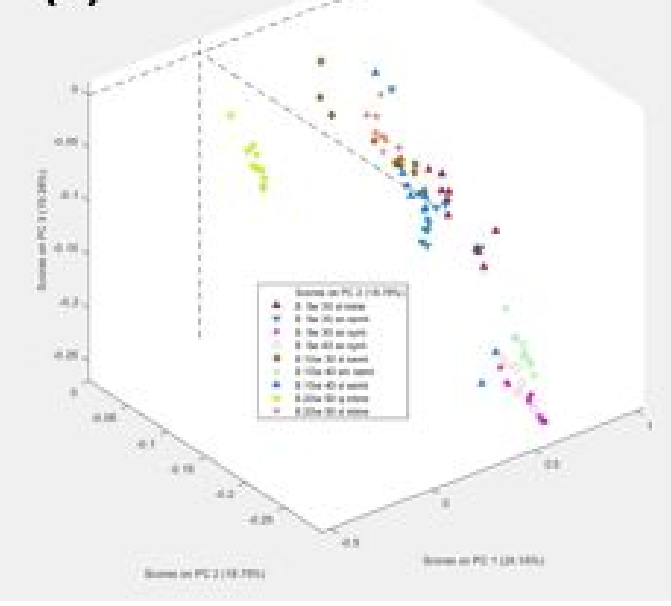

(b)

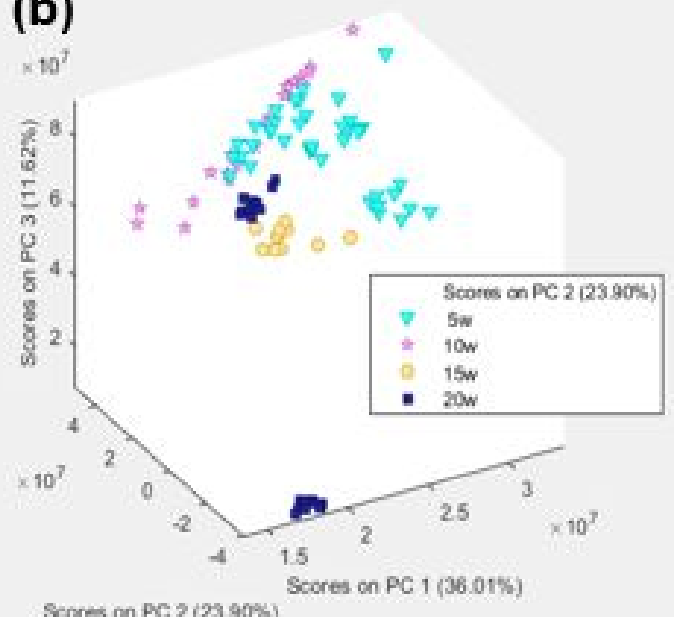

Scores on PC $2(2390 \%)$

Figure S6. Three-dimensional scores plot from the PCA analysis determined from mass spectra for the brand B samples showing base oil type distinction (a) and 
low SAE classification distinction (b). The data was preprocessed with mean centering, 1-Norm and Poisson scaling.
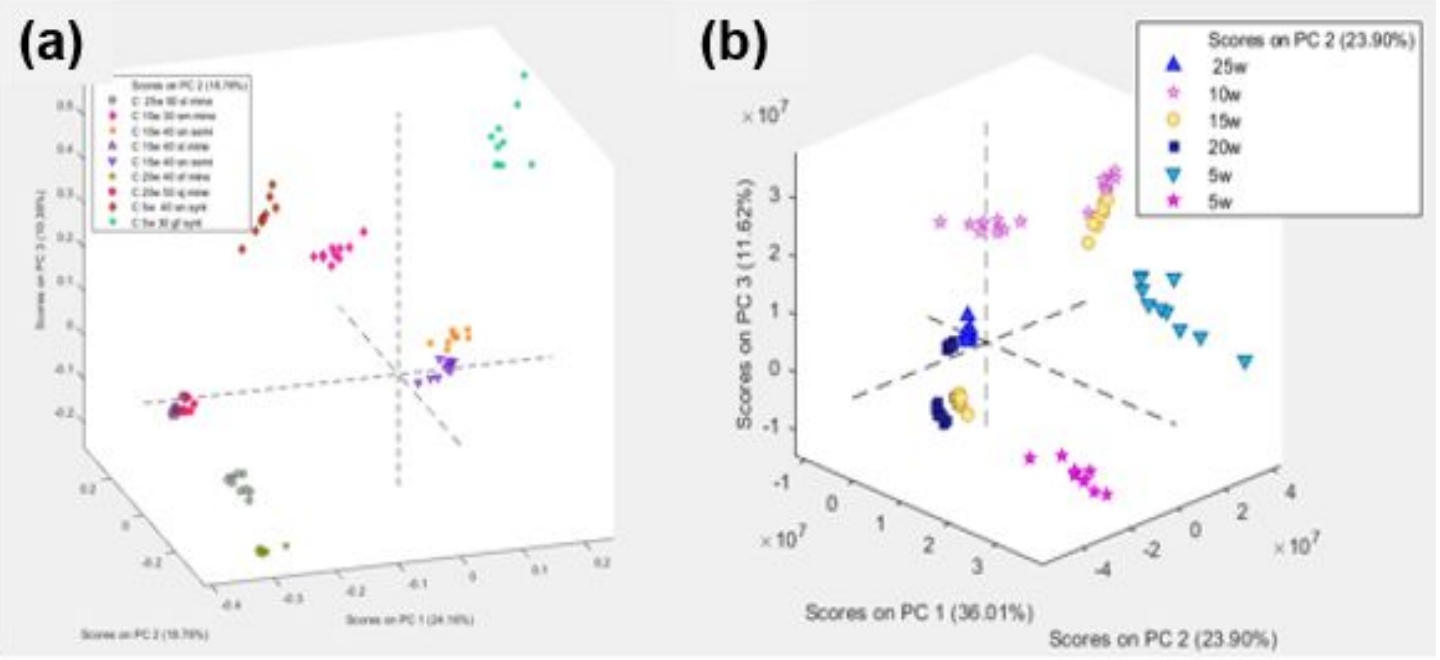

Figure S7. Three-dimensional scores plot from the PCA analysis determined from mass spectra for the brand $\mathrm{C}$ samples showing base oil type distinction (a) and low SAE classification distinction (b). The data was preprocessed with mean centering, 1-Norm and Poisson scaling.

(a)

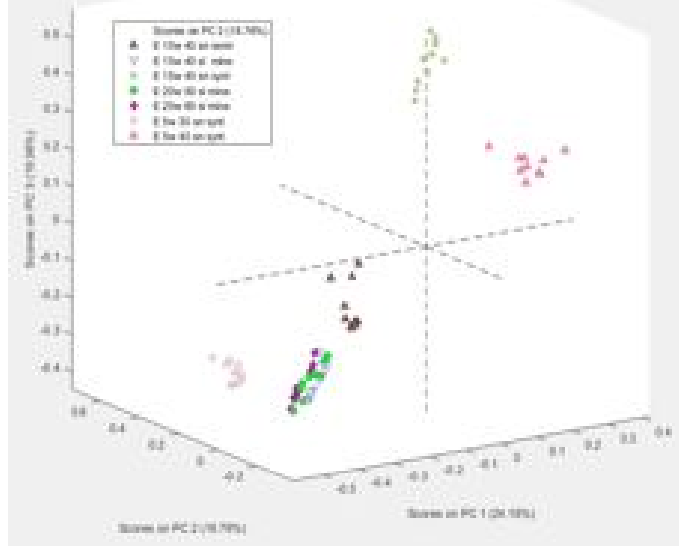

(b)

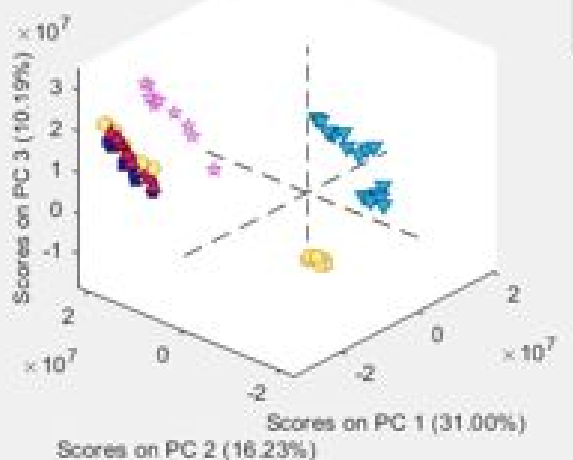

Figure S8. Three-dimensional scores plot from the PCA analysis determined from mass spectra for the brand $D$ samples showing base oil type distinction (a) and Iow SAE classification distinction (b). The data was preprocessed with mean centering, 1-Norm and Poisson scaling. 


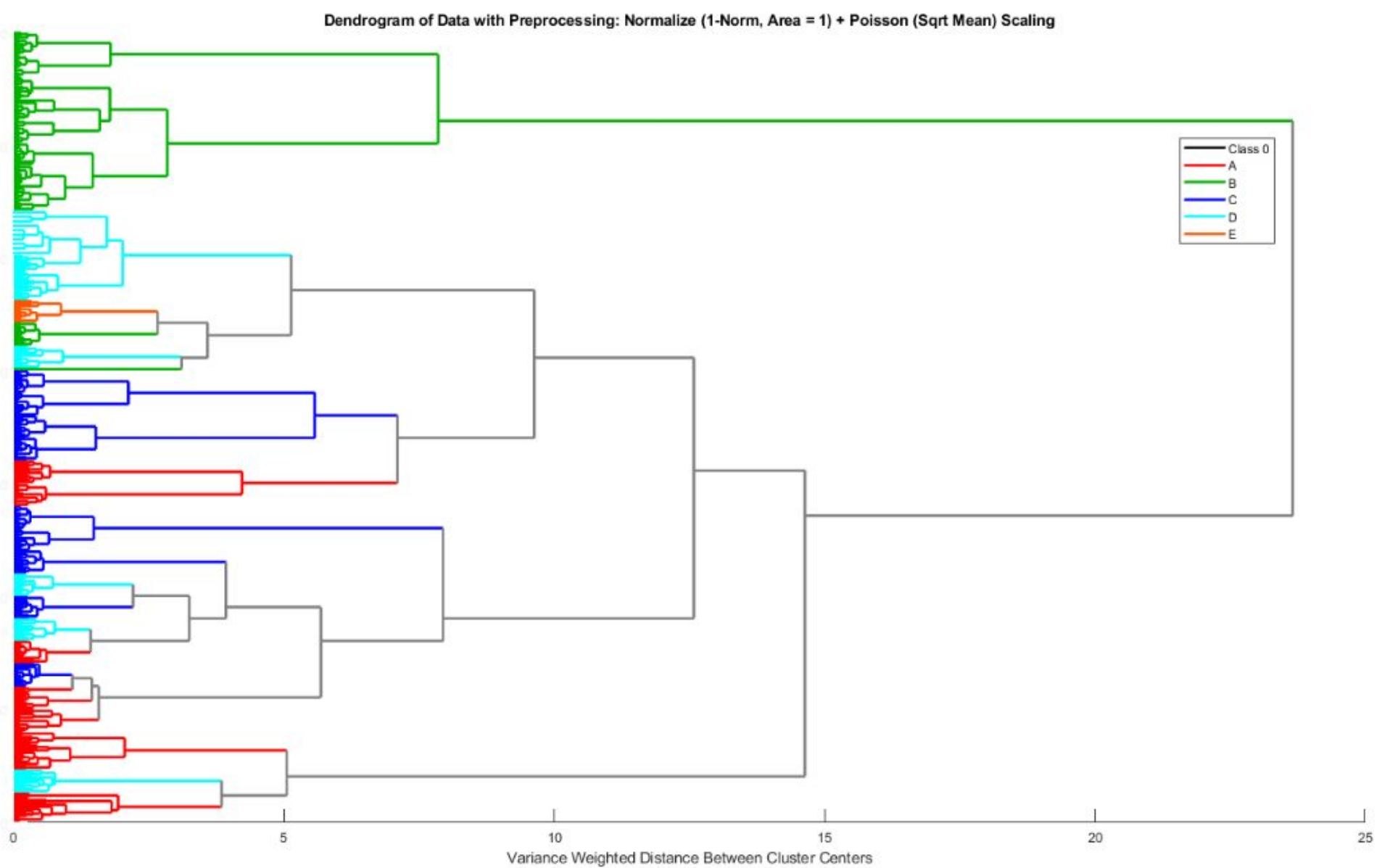

Figure S9. HCA of the DBDI-TOFMS spectra from the profile of the ALOs samples. 

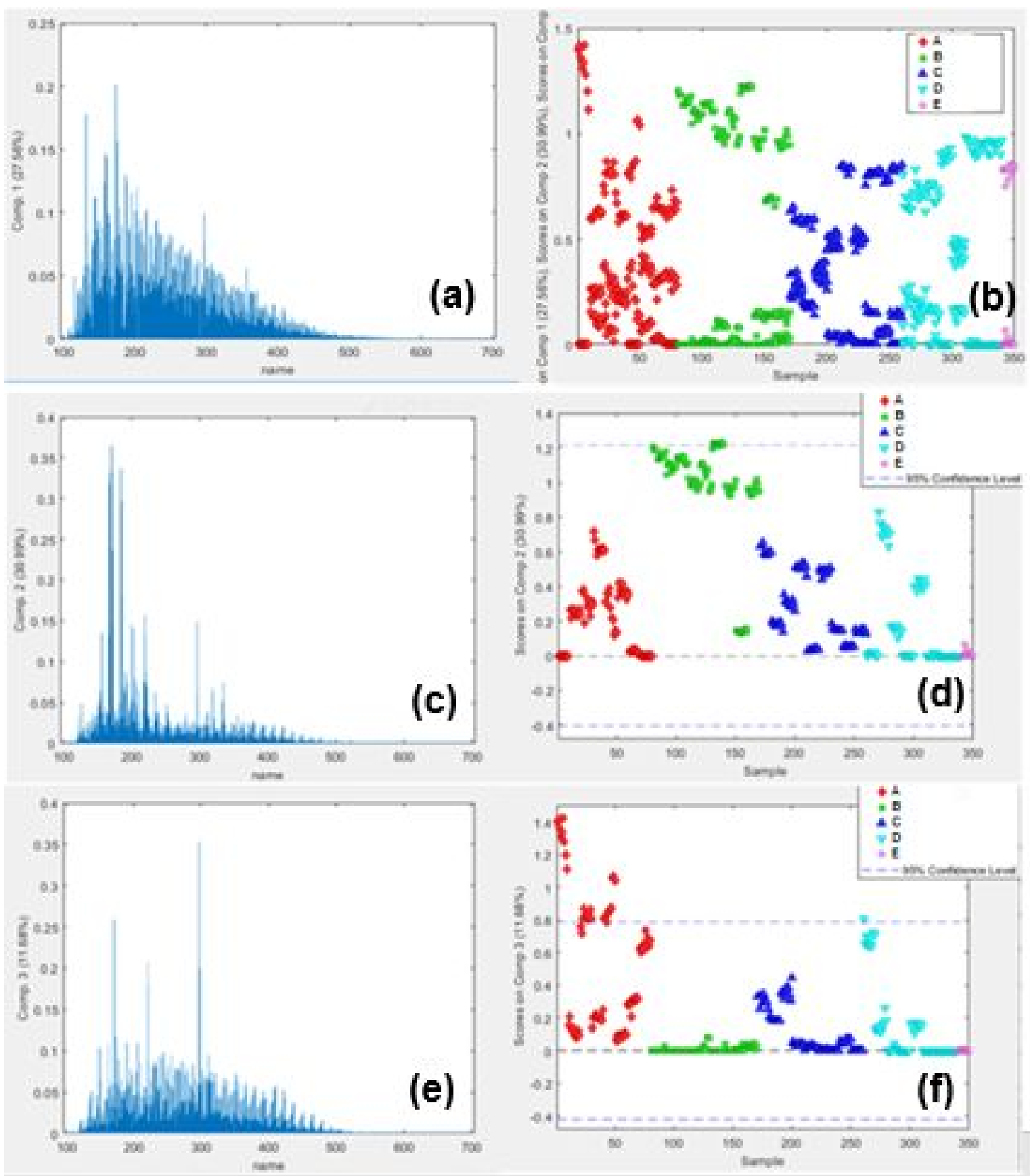

Figure S10. MCR components 1 to 3 from MCR model of DBDI-TOFMS spectra from the profile of the ALOs samples. Loadings on (a) Component 1, (c) Component 2, and (e) Component 3 as a function of the mass (u) and scores plots on (b) Component 1, (d) Component 2, and (f) Component 3 as a function of the mass spectra. 